\title{
El papel de la escuela localmente relevante frente a las actuales teorías del desarrollo. Un acercamiento al enfoque de las capacidades
} humanas

DOI: https://doi.org/10.32870/dse.v0i10.284

\section{Adriana Carro Olvera* José Alfonso Lima Gutiérrez**}

Resumen: La superación de la idea tradicional en el que desarrollo era igual a crecimiento económico condujo a entender al desarrollo como un concepto multidisciplinario en el que toda una diversidad de enfoques pueden contribuir para comprenderlo de una manera integral. Desde diferentes ciencias el concepto evolucionó y las aportaciones en el último medio siglo se multiplicaron; en ese escenario el presente artículo tiene como objetivo analizar el papel que representan las escuelas localmente relevantes desde el enfoque de las capacidades humanas entendido este enfoque como una de las teorías de desarrollo más actuales defendiendo la expansión de las libertades, el desarrollo como construcción de capital social y la reivindicación de la cultura en las comunidades, esto conduce a definir el desarrollo como requerimiento de los espacios locales y regionales ante la economía global. Palabras claves: escuela, capacidades humanas, desarrollo local, capital social, cultura.

\begin{abstract}
Abstrac: Overcoming the traditional idea that development equals economic growth was led to understand development as a multidisciplinary concept that a wide variety of approaches can help to understand in a comprehensive manner. Since the concept evolved different sciences and contributions over the past half century multiplied; in that scenario this article is to analyze the role played by the locally relevant schools from the perspective of human capacities understand this approach as one of the most current development theories advocating the expansion of freedoms, development and capital construction claim social and culture in communities, this leads to define development as a requirement of local and regional areas to the global economy. Keywords: school, human capabilities, local development, social capital, culture.
\end{abstract}

\section{Las diversas nociones sobre el desarrollo}

El concepto de desarrollo ha cambiado históricamente. Si bien el concepto nace al interior de la economía y su explicación inicial se acotó exclusivamente a aspectos relacionados con esta disciplina poco a poco otras ciencias fueron aportando elementos teóricos para comprender al concepto de una manera más amplia.

Derivado del surgimiento y propagación de la civilización cristiano/occidental, el ser humano busca la forma de modificar sus condiciones de vida imaginando y representando escenarios

* Dctora en Desarrollo Regional por el Colegio de Tlaxcala A.C. Profesora-Investigadora del Posgrado en Educación de la Universidad Autónoma de Tlaxcala. Cuerpo académico "Gestión y Políticas Educativas". Correo electrónico: cuerpoacademicofce@gmail.com, acarroo1@yahoo.com.mx

** Doctor en Desarrollo Regional por el Colegio de Tlaxcala A.C. Profesor-Investigador del Posgrado en la Facultad de Derecho, Ciencias Políticas y Criminología de la Universidad Autónoma de Tlaxcala. Correo electrónico: alimagu_1@yahoo.com.mx 
futuros que le permitan - acorde al pensamiento moderno originado en Europa - avanzar y perfeccionarse en los ámbitos de las ideas, de la moral y de la praxis económica con la finalidad de cambiar, de vivir mejor y de construir el futuro o lo que aún no es pero que será. Sin embargo, con la expansión del capitalismo y la aparición de sus contradicciones y de los desequilibrios sociales y territoriales, comienza en el siglo XVIII una serie de reflexiones sobre el estudio de los efectos negativos, así como de sus soluciones.

Al realizar un análisis encontramos que el propio concepto de desarrollo es complejo, profundamente axiológico, multidimensional, constructivista, cualitativo en su esencia e intangible por consecuencia (Boisier, 1999). Algunos antecedentes de esta circunstancia es que el supuesto de avanzar es una invención moderna con una connotación de la civilización cristiano/occidental, pues las civilizaciones y sociedades antiguas - como la mesoamericana - no poseían una noción lineal del tiempo, éste era concebido como un eterno retorno a los orígenes sagrados con una visión circular del tiempo cósmico. El pasado es un presente, reaparece y retorna, pero con el cristianismo se difunde la creencia del fin del mundo y de los tiempos, el cual es irreversible, único, distinto, lineal, finito y personal. Es decir se cristaliza una concepción de tiempo como un transcurrir, un ir al futuro y al cambio.

Rodríguez (2005) asume que este tipo de diferencias radica principalmente en la conformación de las ideas del desarrollo, asegura que es un concepto de connotación pasiva, pero que incluye trasfondos opuestos ${ }^{1}$. La modernidad europea es el primer movimiento histórico que coloca el énfasis en el cambio y en la perfección, las civilizaciones antiguas se resistían a la transformación de sus sociedades y a la muerte (al fin). De esta forma, lo que resulta claro es que la idea de progreso, de futuro, de aspirar a la perfección, de cambio, de transformar a la sociedad, de desarrollo, son voces de la modernidad europea asumiéndolos como valores e ideales universales.

Aunque el concepto tiene diversos antecedentes adquiere acta de formalidad en el léxico público con un discurso del presidente norteamericano Harrys Truman ${ }^{2}$ en 1949, cuando da a conocer el plan Marshall a Grecia y Turquía. Del discurso nacen las palabras de desarrollo y subdesarrollo, donde los países desarrollados indicaban a los subdesarrollados lo que tenían que hacer. Esta visión dominante del desarrollo vinculó estrechamente dos elementos: modernización y crecimiento económico, haciendo hincapié en las condiciones de acumulación de capital, la elevación del consumo y la industrialización (Rodríguez, 2005).

${ }^{1}$ El concepto de desarrollo tiene debates teóricos, estratégicos e ideológicos. Como puede ser el caso del debate ideológico entre los campesinos e indígenas para quienes el desarrollo representa una vía para salir de la pobreza y marginación, y para los otros es un parapeto que les ayuda a mantener los mecanismos de control sobre la población y extracción de los recursos, dando legitimidad para continuar con el estado actual : la desigualdad.

${ }^{2}$ El discurso reitera el emprendimiento de un programa audaz que permita que los beneficios de los avances científicos norteamericanos, así como su progreso industrial sirvan para la mejoría y crecimiento de las áreas subdesarrolladas con un programa de desarrollo justo. 
El papel de la escuela localmente relevante frente a las actuales teorías del desarrollo. un acercamiento al enfoque de las capacidades humanas

Las teorías del desarrollo tienden a ser distintas entre sí debido a que sus sistemas conceptuales se construyen en circunstancias históricas específicas privilegiando el abordaje de determinados ámbitos — diferentes pero complementarios — de sociedad. Se distinguen por la prioridad analítica que le otorgan a ciertos actores, agentes, estructuras, relaciones de poder y de dominación que influyen en el proceso de desarrollo, que se hacen y rehacen históricamente. El siguiente cuadro expresa sintéticamente la evolución de las teorías del desarrollo.

CUADRO 1

LAS TEORÍAS DEL DESARROLLO EN EL TIEMPO: SUS ORÍGENES, SUS PRINCIPALES CONCEPTOS, SUS SUPUESTOS NORMATIVOS Y SUS TEÓRICOS REPRESENTATIVOS

\begin{tabular}{|c|c|c|c|c|}
\hline $\begin{array}{l}\text { Enfoques } \\
\text { teóricos }\end{array}$ & Periodo & Conceptos básicos & Propuestas de política & $\begin{array}{c}\text { Autores } \\
\text { representativos }\end{array}$ \\
\hline El debate clásico & $\begin{array}{l}\text { Siglo XVIII y XIX } \\
\text { y primeras dos } \\
\text { décadas del siglo } \\
\text { XX }\end{array}$ & $\begin{array}{ll}\text { - } & \text { Crecimiento de } \\
& \text { la riqueza de las } \\
& \text { naciones } \\
\text { - } \quad \text { División del trabajo } \\
\text { - } \quad \text { Modernidad } \\
\text { - } \quad \text { Orden y progreso } \\
\text { - } \quad \text { Enambio social } \\
\text { conflicto y crisis del } \\
\text { capitalismo }\end{array}$ & $\begin{array}{l}\text { - Desde la perspectiva liberal: } \\
\text { situar al mercado como la } \\
\text { institución que ordena y regula } \\
\text { el proceso económico. Aunado } \\
\text { a ello, se asume la necesidad } \\
\text { de la armonía, del orden, del } \\
\text { progreso, de la solidaridad } \\
\text { y de la racionalización de las } \\
\text { sociedades } \\
\text { Desde la tradición marxista: } \\
\text { el tránsito de una sociedad } \\
\text { organizada bajo el modo de } \\
\text { producción comunista }\end{array}$ & $\begin{array}{l}\text { Adam Smith } \\
\text { David Ricardo, } \\
\text { John Stuart Mill. } \\
\text { Augusto Comte, } \\
\text { Émile Durkheim } \\
\text { Max Weber } \\
\text { Karl Marx }\end{array}$ \\
\hline $\begin{array}{l}\text { La teoría de la } \\
\text { modernización }\end{array}$ & 1945-1968 & $\begin{array}{ll}\text { - } & \text { Sociedad } \\
\text { tradicional/ sociedad } \\
\text { moderna } \\
\text { - } \\
\text { Despegue o take-off } \\
\text { Difusionismo } \\
\text { Efecto de derrame } \\
\text { (spill over) }\end{array}$ & $\begin{array}{l}\text { La industrialización y el } \\
\text { consumismo masivo para } \\
\text { abandonar las condiciones de } \\
\text { sociedad tradicional y tender al } \\
\text { desarrollo transitado por varias } \\
\text { etapas sucesivas. Con base en } \\
\text { ello, el crecimiento económico } \\
\text { derivara por añadidura en el } \\
\text { bienestar social generalizado }\end{array}$ & $\begin{array}{l}\text { W. Arthur Lewis, } \\
\text { Walt W. Rostow, } \\
\text { Bert F. Hoselitz, } \\
\text { Albert O. Hirscham, } \\
\text { Gino Germani, } \\
\text { y otros. }\end{array}$ \\
\hline
\end{tabular}




\begin{tabular}{|c|c|c|c|c|}
\hline $\begin{array}{l}\text { La reflexión } \\
\text { latinoamericana }\end{array}$ & $1950-1975$ & $\begin{array}{ll}\text { - } & \text { Centro/periferia } \\
\text { - } & \text { Heterogeneidad } \\
\text { - } & \text { Difusión del } \\
& \text { progreso técnico } \\
\text { - } & \text { Dependencia } \\
\text { - } & \text { Desarrollo } \\
& \text { dependiente } \\
\text { - } & \text { Subdesarrollo } \\
\text { - } & \text { Colonialismo interno }\end{array}$ & $\begin{array}{l}\text { - La CEPAL propuso- con base } \\
\text { a la intervención del sector } \\
\text { publico- la industrialización } \\
\text { sustitutiva de importaciones } \\
\text { para hacer frente al deterioro de } \\
\text { los términos de intercambio y } \\
\text { para procurar la autonomía del } \\
\text { capitalismo latinoamericano. } \\
\text { - Las versiones radicales de } \\
\text { la Teoría de la Dependencia } \\
\text { surgieron la ruptura con las } \\
\text { relaciones capitalistas de } \\
\text { producción para abandonar el } \\
\text { desarrollo dependiente. }\end{array}$ & $\begin{array}{l}\text { Raúl Prebisch, } \\
\text { Aníbal Pinto y } \\
\text { Celso Furtado. } \\
\\
\text { - Andre } \\
\text { Gunder } \\
\text { Frank, } \\
\text { Fernando } \\
\text { Henrique } \\
\text { Cardoso, } \\
\text { Theotonio } \\
\text { Dos Santos, } \\
\text { Ruy Mauro } \\
\text { Marini, } \\
\text { Pablo } \\
\text { González } \\
\text { Casanova } \\
\text { y otros. }\end{array}$ \\
\hline $\begin{array}{l}\text { El desarrollo } \\
\text { adjetivado }\end{array}$ & $\begin{array}{l}\text { Desde la década } \\
\text { de los setenta }\end{array}$ & 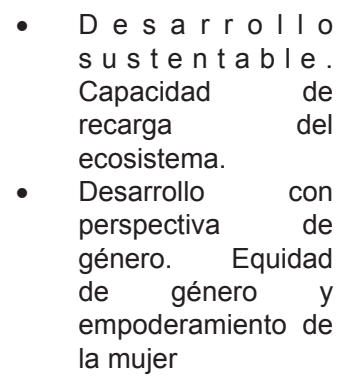 & $\begin{array}{l}\text { - Considerar las implicaciones } \\
\text { medioambientales del desarrollo } \\
\text { económico, así como el papel de la } \\
\text { mujer en este proceso. }\end{array}$ & $\begin{array}{l}\text { Variedad de } \\
\text { consultores de la } \\
\text { ONU y de activistas } \\
\text { y académicos } \\
\text { universitarios }\end{array}$ \\
\hline $\begin{array}{l}\text { Versiones } \\
\text { contemporáneas } \\
\text { de la economía } \\
\text { neoclásica(teoría } \\
\text { económica } \\
\text { monetarista) }\end{array}$ & $\begin{array}{l}\text { Desde la década } \\
\text { de los setenta }\end{array}$ & $\begin{array}{ll}\text { - } & \text { Libertad } \\
\text { - } & \text { Inflación definida } \\
& \text { como fenómeno } \\
& \text { monetario } \\
\text { - } & \text { Centralidad del } \\
& \text { mercado } \\
\text { - } & \text { Estado mínimo } \\
\text { - } & \text { Disciplina fiscal } \\
\text { - } & \text { Privatización }\end{array}$ & $\begin{array}{l}\text { - Apostar por un desarrollo } \\
\text { exógeno con base en el equilibrio } \\
\text { macroeconómico y la intervención } \\
\text { mínima del sector público en la } \\
\text { economía. La procuración de la } \\
\text { disciplina fiscal, la apertura comercial } \\
\text { y financiera, y la centralidad del } \\
\text { mercado en el proceso económico y } \\
\text { en la asignación de recursos derivara } \\
\text { en el desarrollo de las naciones }\end{array}$ & $\begin{array}{l}\text { Milton Friedman, } \\
\text { Ronald McKinon, } \\
\text { Anne O.Krueger, } \\
\text { Jeffrey Sachs }\end{array}$ \\
\hline $\begin{array}{l}\text { Enfoques de la } \\
\text { transición a la } \\
\text { democracia }\end{array}$ & $\begin{array}{l}\text { Desde la década } \\
\text { de los setenta }\end{array}$ & $\begin{array}{l}\text { - Transición desde } \\
\text { regímenes } \\
\text { autoritarios } \\
\text { Democratización } \\
\text { de los sistemas } \\
\text { políticos. } \\
\text { Accountability } \\
\text { horizontal }\end{array}$ & $\begin{array}{l}\text { - Abandonar los regímenes burocrático- } \\
\text { autoritarios caracterizados por el uso } \\
\text { de la represión, y transitar hacia la } \\
\text { democratización de los sistemas } \\
\text { políticos mediante la realización de } \\
\text { procesos electorales y la apertura a } \\
\text { la participación de organizaciones } \\
\text { sociales y políticas. }\end{array}$ & $\begin{array}{l}\text { Guillermo O'Donell, } \\
\text { Philippe } \\
\text { C. } \\
\text { Laurence } \\
\text { y otros. }\end{array}$ \\
\hline
\end{tabular}




\section{El papel de la escuela localmente relevante frente a las actuales teorías del desarrollo. un acercamiento al enfoque de las capacidades humanas}

\begin{tabular}{|c|c|c|c|c|}
\hline $\begin{array}{l}\text { Enfoques } \\
\text { territoriales } \\
\text { del desarrollo } \\
\text { endógeno }\end{array}$ & $\begin{array}{l}\text { Desde la década } \\
\text { de los ochenta }\end{array}$ & $\begin{array}{ll}\text { - } & \text { Territorio } \\
\text { - } & \text { Desigualdades } \\
\text { - } & \text { Eerritoriales } \\
& \text { Economías de } \\
\text { - } & \text { Deslomeración } \\
\end{array}$ & $\begin{array}{l}\text { - Procurar el desarrollo de los espacios } \\
\text { locales y aprovechar sus ventajas } \\
\text { comparativas y competitivas para } \\
\text { insertarse en la economía mundial }\end{array}$ & $\begin{array}{l}\text { Antonio Vázquez } \\
\text { Banquero, } \\
\text { Manuel Castells, } \\
\text { Milton Santos, } \\
\text { Sergio Boisier, Enrique } \\
\text { Dussel Peters }\end{array}$ \\
\hline $\begin{array}{l}\text { Enfoque de las } \\
\text { capacidades } \\
\text { humanas }\end{array}$ & $\begin{array}{l}\text { Desde la década } \\
\text { de los noventa }\end{array}$ & $\begin{array}{ll}\text { - } & \text { Desarrollo como } \\
& \text { libertad } \\
\text { - } & \text { Capacidades } \\
\text { - } & \text { Calidad de vida } \\
\text { - } & \text { Interconexiones }\end{array}$ & $\begin{array}{l}\text { - Formar y estimular las capacidades } \\
\text { humanas que contribuyan a la } \\
\text { expansión de las libertades }\end{array}$ & Amartya Sen \\
\hline $\begin{array}{l}\text { Enfoque del } \\
\text { capital social }\end{array}$ & $\begin{array}{l}\text { Desde mediados } \\
\text { de la década de } \\
\text { los noventa }\end{array}$ & $\begin{array}{ll}\text { - } & \text { Capital social } \\
\text { - } & \text { Cultura } \\
\text { - } & \text { Desarrollo local }\end{array}$ & $\begin{array}{l}\text { - Aprovechar las expresiones } \\
\text { culturales de las comunidades } \\
\text { y las relaciones de confianza y } \\
\text { reciprocidad entre los individuos para } \\
\text { organizar proyectos del desarrollo } \\
\text { autogestivo. }\end{array}$ & $\begin{array}{l}\text { Robert Putnam, } \\
\text { James Coleman, } \\
\text { Bernardo Kliksberg, } \\
\text { y otros. }\end{array}$ \\
\hline $\begin{array}{l}\text { Nuevo } \\
\text { institucionalismo } \\
\text { económico }\end{array}$ & $\begin{array}{l}\text { Desde la década } \\
\text { de los noventa }\end{array}$ & $\begin{array}{ll}\text { - } & \text { Instituciones } \\
& \text { Racionalidad } \\
& \text { limitada } \\
\text { - } & \text { Costos de } \\
& \text { transacción, } \\
& \text { derechos de } \\
\text { propiedad y } & \text { contratos } \\
\text { - } & \text { Elección publica }\end{array}$ & $\begin{array}{l}\text { - Reformar, corregir y fortalecer las } \\
\text { instituciones para contrarrestar } \\
\text { las fallas del mercado, mejorar el } \\
\text { desempeño económico, garantizar la } \\
\text { transacción económicas y disminuir } \\
\text { los costos de estas }\end{array}$ & $\begin{array}{l}\text { Douglass C. North, } \\
\text { Oliver E. Williamson, } \\
\text { Ronald Coase, } \\
\text { y otros. }\end{array}$ \\
\hline $\begin{array}{l}\text { Análisis de los } \\
\text { agentes y actores } \\
\text { sociales }\end{array}$ & $\begin{array}{l}\text { Desde la década } \\
\text { de los noventa }\end{array}$ & $\begin{array}{ll}\text { - } & \text { Diversidad de } \\
\text { - } & \text { formas de vida } \\
\text { - } & \text { Movimientos social } \\
& \text { sociales }\end{array}$ & $\begin{array}{l}\text { - Reconocer la racionalidad de } \\
\text { actores y agentes sociales como } \\
\text { los movimientos ambientalistas, las } \\
\text { mujeres organizadas y las ONG'S } \\
\text { para aprovechar su participaciones la } \\
\text { planeación del desarrollo. }\end{array}$ & $\begin{array}{l}\text { John Friedman, } \\
\text { Arturo Escobar, } \\
\text { Carlos Walter } \\
\text { Porto Goncalves, } \\
\text { y otros }\end{array}$ \\
\hline $\begin{array}{l}\text { Enfoques } \\
\text { neokeynesianos } \\
\text { (críticas al } \\
\text { fundamentalismo } \\
\text { de mercado) }\end{array}$ & $\begin{array}{l}\text { Principios del } \\
\text { siglo XXI }\end{array}$ & $\begin{array}{ll}\text { - } & \text { Estado } \\
\text { Déficit de } \\
\text { gobernabilidad en la } \\
\text { economía global } \\
\text { - } \quad \text { Gobernanza global }\end{array}$ & $\begin{array}{l}\text { - Reformas a los organismos } \\
\text { financieros internacionales para } \\
\text { lograr una adecuada gobernación y } \\
\text { gestión de la globalización, y fomentar } \\
\text { la asociación y la complementariedad } \\
\text { entre el estado y el mercado. }\end{array}$ & Joseph E. Stiglitz \\
\hline
\end{tabular}

Fuente: Enríquez, Isacc (2009) en La construcción social de las teorías del desarrollo. 
El surgimiento del Estado-nación moderno, con la generación y expansión del capitalismo y con las apariciones de las primeras contradicciones sociales en este modelo de producción, fue esbozado en el marco del pensamiento europeo moderno desde el siglo XVIII, cuyas reflexiones planteadas tuvieron como preocupación central el crecimiento de la riqueza de las naciones, aquí encontramos a Adam Smith, fundador de la economía política clásica; quien señaló que la riqueza de las naciones —alimentada por la acumulación de capital— es propiciada por el trabajo. David Ricardo con la acumulación de los excedentes y sus rendimientos decrecientes. John Stuart Mill afirmando que el progreso económico es sinónimo de civilización. Augusto Comte apostando a una estructura más armoniosa del capitalismo mediante la racionalidad de la ciencia con su pensamiento positivista. Con Karl Marx la explicación de la dinámica, las contradicciones y las crisis del modo de producción capitalista. Émile Durkheim con la preocupación por el orden social justo con regulación moral y la obra de Max Weber para interpretar la complejidad del cambio social y la naturaleza del capitalismo reivindicando la acción de la voluntad humana en el proceso histórico (Enríquez, 2009).

Para una mejor comprensión del concepto, se realiza una distinción entre teorías del desarrollo y modelos de crecimiento económico ${ }^{3}$ hasta antes de la década de los setenta del siglo XX, los teóricos hablaban de crecimiento económico ilimitado; sin embargo, con la recesión inflacionaria, el deterioro medioambiental, el crecimiento demográfico y la crisis energética, comenzó a hablarse de los límites de crecimiento, trayendo como consecuencia que los estudios del desarrollo se hicieran complejos en sus conceptualizaciones al abordar objetos de estudio como el medio ambiente y su preservación, el papel de la mujer en la economía, la democratización de los sistemas políticos y los movimientos sociales, la cultura y las comunidades locales. Fue entonces como las instituciones y las regiones dejaron de definir al desarrollo como sinónimo de crecimiento económico.

Mientras la economía clásica hizo del crecimiento económico su tema central, la neoclásica lo hizo con la distribución económica. El concepto de desarrollo es una idea política de la posguerra y de las Naciones Unidas; inicialmente el concepto de desarrollo económico fue asociado a crecimiento y el PIB per cápita fue la medida corriente del nivel de desarrollo ayudando a consolidar el dominio de las economías en el tema de desarrollo. Posteriormente el Programa de las Naciones Unidas con el PNUD tiene una nueva forma de medir el desarrollo a través del concepto de Índice de Desarrollo Humano con tres componentes: calidad de vida, longevidad y nivel de conocimiento.

En los setentas nacen las posturas que se denominan como el otro desarrollo dando preponderancia a las formas de desarrollo surgidas desde abajo, en pequeña escala, descentralizadas,

${ }^{3}$ Las teorías del desarrollo consisten en el estudio cualitativo de un proceso multidimensional que remite al mejoramiento del nivel de vida de las poblaciones y a la transformación de las instituciones y estructuras de la sociedad. Las teorías de crecimiento estudian el comportamiento de una economía y las posibilidades de expansión en su tamaño. Tanto las teorías del desarrollo como las teorías y modelos económicos, más que ser excluyentes, son complementarias puesto que una consideración necesaria para el logro del bienestar social es el crecimiento de la riqueza de las sociedades (Enríquez, 2009). 
El papel de la escuela localmente relevante frente a las actuales teorías del desarrollo. un acercamiento al enfoque de las capacidades humanas

respetuosas de la ecología, que fueran democráticas y humanas: el desarrollo de las necesidades básicas, tomando el enfoque de la Organización Internacional del Trabajo (OIT) destacando que no puede existir desarrollo mientras no se satisfagan las necesidades básicas de las personas como alimentación, salud, educación y participación. Es hasta el año de 1995 cuando se publica por el Secretario General de las Naciones Unidas una Agenda para el Desarrollo; llevando el término al plano de lo intangible y abriendo las puertas a disciplinas distintas de la economía.

Actualmente se discuten otros referentes como los índices de prosperidad y felicidad. El índice de Prosperidad Legatum ${ }^{4}$ toma como referencia en cada país, la economía, oportunidades para emprendimientos, gobernabilidad, educación, salud, seguridad y protección, libertad personal y capital social. En el reino de Bután ${ }^{5}$ importa más la alegría de sus habitantes que la productividad económica. El gobierno de ese país asiático cercano a la cordillera del Himalaya, entre India y China, sustituyó el indicador de Producto Interno Bruto por el Índice de Felicidad Nacional Bruta ${ }^{6}$ a fin de crear las condiciones necesarias que harían felices a sus ciudadanos, por ejemplo: el equilibrio entre el tiempo dedicado al trabajo y al descanso; esta iniciativa se extendió como filosofía en el 2012 en la Organización de la Naciones Unidas (ONU), la cual se ha encargado de promoverla: $E l$ mundo necesita un nuevo paradigma económico que reconozca la paridad de los tres pilares del desarrollo sostenible, el social, el económico y el medioambiental porque juntos definen la felicidad global.

\section{El desarrollo de las capacidades humanas y el desarrollo local endógeno}

Quizá una de las teorías de desarrollo que adquiere mayor relevancia durante los años noventa es la relacionada con el enfoque de las capacidades humanas. Bajo este enfoque el desarrollo es concebido como un proceso de expansión de las libertades valoradas y disfrutadas por los individuos a partir de la formación y fomento de las capacidades humanas que privilegian una forma de vida satisfactoria para ellos. El enfoque de capacidades ha trascendido de la teoría a la vida de las instituciones, tal es el caso de la aplicación en indicadores como el Índice de Desarrollo Humano difundido por el programa de las Naciones unidas para el desarrollo (PNUD) e influye en el diseño de políticas sociales en distintas partes del mundo. Esa noción supone asegurar la nutrición y la salud adecuadas, la disposición de un espacio decoroso para vivir, el acceso a una educación de calidad y por supuesto, la oportunidad de usar los conocimientos en el desempeño de una actividad productiva o creadora de cualquier índole.

${ }^{4}$ El Índice de Prosperidad Legatum agrupa a 110 países, basando sus mediciones con Indicadores de Desarrollo Mundial, IDH, Banco Mundial, OCDE, Encuesta Nacional de Valores, etc. Desde el 2010 Noruega encabeza la lista del informe.

${ }^{5}$ País que reconoce la supremacía de la felicidad nacional por encima de los ingresos nacionales desde principios de los 70 , cuando adoptó el concepto de un Índice de Felicidad Nacional Bruta para sustituir al más tradicional Producto Interior Bruto.

${ }^{6}$ La Asamblea General de la ONU el 12 de julio de 2012 decretó el 20 de marzo Día Internacional de la Felicidad, para reconocer la relevancia de la felicidad y el bienestar como aspiraciones universales de los seres humanos y la importancia de su inclusión en las políticas de gobierno. 
A esto se refiere el premio nobel de economía de 1998 Amartya Sen (1997), cuando advierte la necesidad de concentrarse en la promoción de capacidades humanas para ampliar la libertad de opción de la gente y referenciar que al Estado le corresponde dotar a sus ciudadanos de esas aptitudes básicas que despejan el camino hacia el bienestar. La postura teórica tiene un enfoque integral, ya que no se reduce al concepto de desarrollo como crecimiento del producto interno bruto y del producto per cápita o a la acumulación de la riqueza, se amplía a dimensiones como los derechos humanos, la democracia en los sistemas políticos, las garantías de transparencia, el acceso a la educación, a la seguridad social, a los servicios sociales, a una vida larga y saludable y el respeto a la cultura local.

Esta posición implica reconocer la relevancia del sector público en la creación de esas oportunidades sociales que faciliten la participación de los individuos en el proceso económico, así como la expansión de las capacidades humanas y el mejoramiento de la calidad de vida, de tal manera que no se reduzcan a receptores pasivos de las políticas sociales; es decir, el Estado y la sociedad en general, más que proporcionar servicios acabados, tienen la función de ayudar mediante la provisión y expansión de las capacidades humanas. Es así como se propone que para poder establecer un desarrollo local o endógeno se requiere como base la formación, acumulación y consolidación del capital social, argumentando que al rescatar la relevancia de la cultura y al formularse proyectos autogestivos, las comunidades trascenderían y revertirían las condiciones de pobreza y marginación.

El desarrollo como construcción de capital social y reivindicación de la cultura en las comunidades está íntimamente relacionado con la cohesión social, con las formas de gobierno y con expresiones culturales y comportamientos sociales que hacen de la sociedad un ente comunitario, siendo más que la suma de los individuos; es la forma de considerar los valores, códigos éticos y simbólicos de una sociedad que impulsan a los individuos en comunidad para lograr un desarrollo económico, pero éste es consecuencia implícita de su bienestar social y no un objetivo repleto de indicadores para demostrar el éxito como sucede bajo otros modelos económicos.

En este tipo de enfoque se analiza la construcción autogestiva del desarrollo "desde abajo", desde las comunidades. De esta manera cuando se habla del desarrollo como reivindicación de los espacios locales y regionales hacemos referencia a los enfoques del desarrollo endógeno; el cual señala la importancia que adquieren los espacios locales ante la globalización, así como la relevancia de la planeación orientada al abatimiento de las desigualdades territoriales. Alburquerque (2003) define al desarrollo local como un proceso endógeno registrado en pequeñas unidades territoriales con agrupamientos humanos, capaz de promover un dinamismo económico para la mejora de la calidad de vida de la población. Arocena (1997) por su parte menciona que el desarrollo local no es pensable si no se inscribe en la racionalidad globalizante de los mercados, pero tampoco es viable si no se plantea sus raíces en las diferencias identitarias que lo harán un proceso habitado por el ser humano. 

enfoque de las capacidades humanas

En este esquema se observa que la reestructuración del Estado debe impulsar formas nuevas en la gestión pública como es la política de desarrollo local y en la que se pueden identificar tres dimensiones: una económica, en la que los empresarios locales usan su capacidad para organizar los factores productivos locales con niveles de productividad suficientes para ser competitivos en los mercados; otra, sociocultural, en que los valores y las instituciones sirven de base al proceso de desarrollo; y, finalmente, una dimensión político administrativa en que las políticas territoriales permiten crear un entorno económico local favorable.

El desarrollo endógeno se produce como resultado de un fuerte proceso de articulación de actores locales y de variadas formas de capital intangible (identidad, cooperación, valores, solidaridad); la concepción local es presentada como una posibilidad de retorno a formas sociales mejores en las que se rescaten los valores comunitarios, la participación y la suma de actores endógenos.

\section{Las escuelas y su función social}

Existen dos miradas polarizadas de la escuela, una que responde a la perspectiva objetivista en sociología y privilegia el análisis de las funciones, la estructura y los roles, y otra más ligada a la perspectiva subjetivista, que atiende a las experiencias de los actores, los significados que éstos les asignan a la vida escolar, las pautas informales de conducta vigentes en ella, los intereses de los grupos involucrados, etcétera (Brigido, 2006). La visión objetivista está representada por el enfoque funcionalista y tiene a Parsons como principal referente ${ }^{7}$. Esta visión se asocia con la sociología de Durkheim, también se puede incluir la perspectiva reproductivista que, como el funcionalismo, tiene una representación estructuralista de la escuela, pero asume una postura crítica frente al modelo que presenta el funcionalismo. El reproductivismo pone en tela de juicio el carácter integrador de las funciones que cumple la escuela y destaca la forma en que esta institución sirve a los intereses de las clases dominantes.

La visión subjetivista se inspira, en la sociología de Max Weber ${ }^{8}$ y se encuentra reflejada en diferentes corrientes de pensamiento, algunas afines a la tradición del consenso, como el interaccionismo simbólico, otras vinculadas a la del conflicto, como la etnometodología, la nueva sociología de la educación y en cierta medida la fenomenología. Obviamente, la forma como se conciba el cometido primordial de la escuela, o sea, su función de inculcación de la cultura (socialización/ educación) dependerá de cuál de esas orientaciones se elija para definirla y caracterizarla.

7 El funcionalismo estructural es el conocido trabajo de Parsons. Para este enfoque, la escuela es una sociedad en miniatura, un pequeño sistema social estructurado de una manera particular, que cumple un conjunto de funciones, tanto manifiestas como latentes, y se relaciona con el entorno de múltiples formas. La estructura implica un conjunto de relaciones (roles) más o menos estables que permiten definir la forma en que ella está organizada, tanto de los miembros como de la escuela en su conjunto.

8 La perspectiva subjetivista de Marx Weber en el análisis de la escuela pone el énfasis en dos aspectos fundamentales de la vida escolar: los significados subjetivos de los actores y la cultura de la escuela, y por otra, los conflictos que se producen en ellas. 
La postura interaccionista sostiene que el condicionamiento estructural está por encima de los intereses y las disposiciones de los actores, este enfoque cuestiona el ideal del modelo clásico según el cual la escuela está al servicio del desarrollo personal. Ponen al día los conflictos anidados en las interacciones en el seno de la clase, el juego cruzado de los estereotipos, el personificado por el docente, ese modelo de virtud embestido por la autoridad sagrada de la sociedad (Durkheim, 1974).

Los actores de la vida escolar tienen sus propios significados (sobre la escuela, los maestros, la enseñanza, el aprendizaje, los contenidos del aprendizaje, etc.). Estos significados, y la forma en que se interpretan por medio de las prácticas de sus actores y los contenidos de la enseñanza, se traducen en conductas, actitudes, valoraciones, etc.; cuyo resultado es un "clima" o un "estilo de vida" propio de la escuela. La escuela legitima un tipo de cultura; ésta representa las pautas de conducta, conocimientos y valores de los estratos de la población. Un aspecto importante de la cultura escolar ${ }^{9}$ son los rituales, los cuales son un acto comunitario, rico en simbolismos, que expresan determinados valores compartidos, y que sirven para crear un sentimiento de pertenencia a la institución, dando un sentido a las actividades de quienes pertenecen a un centro escolar.

La valoración de la escuela se mueve con ambivalencia, por una parte se reconoce su necesidad y aportación a los individuos y a la sociedad en su conjunto, y por otra recibe habituales críticas respecto a su eficacia y estructura. En los años ochenta, Sarramona (2000) hizo una agrupación de las principales críticas a la escuela:

a) Crítica conservadora. Se trata de una crítica que remite a tiempos pasados de selección y dependencia de la escuela respecto a los poderes fácticos de la economía y la ideología, y que en el profesorado toma formas de organización y metodología tradicionales.

b) Crítica humanista. Es la que se ampara en una concepción integral de la educación, en búsqueda de los valores más clásicos de la cultura, para rechazar las posibles desviaciones de la educación escolar hacia el pragmatismo y la preparación para el mundo laboral, rechaza la instauración de criterios de calidad que se vinculan con resultados académicos cuantificables.

c) Crítica neomarxista. Especialmente en Francia, aparecieron en la década de los setenta una serie de autores (Bourdieu, Baudelot, Establet, Passeron, Snyders...) que se destacaron por la crítica dirigida a la escuela como institución perpetuadora de la sociedad capitalista y las diferencias de clase a través de su función selectiva y de imposición de la cultura burguesa. Las consecuencias de esta actuación de la escuela como menciona Althusser (1974), es la marginación de las culturas populares y la perpetuación del aparato ideológico del Estado.

9 Cada actor de la vida escolar pertenece a una familia en la cual ha sido socializado. Durante el proceso de socialización se aprenden pautas culturales que, por las condiciones en que se adquieren, se fijan con especial fuerza en el individuo. Cuando las normas y valores mantenidos por la familia son coherentes con los que sostiene la escuela, el proceso de adaptación a la cultura escolar es más fácil y las posibilidades de responder adecuadamente a las expectativas de la escuela son mayores. 
El papel de la escuela localmente relevante frente a las actuales teorías del desarrollo. un acercamiento al enfoque de las capacidades humanas

d) Crítica tecnológica. En los años setenta surgió una corriente crítica denominada "desescolarizadora”, que demandó la supresión simple de la obligatoriedad de la educación escolar, proclamando la bondad de la educación proporcionada por los sistemas no formales e informales. Autores como Reimers (1999) y especialmente Illich (2006) fueron los precursores de esta propuesta, que tuvo amplio eco internacional por su radicalidad.

Las instituciones por el mero hecho de su existencia, controlan la conducta humana al establecer patrones de conducta que orientan el comportamiento individual en un sentido en contra de otros múltiples teóricamente posibles; las instituciones reflejan y hasta cierto punto mediatizan los valores y las relaciones sociales de una sociedad determinada.

Fernández (2007) sugiere que la estructuración de los aprendizajes originada en la clase social y en la organización escolar requiere analizarse modelizando las relaciones que conservan los diseños institucionales de la educación escolarizada con la matriz básica de las políticas sociales predominantes en un país o con el régimen de provisión del bienestar.

La investigación educativa en América Latina desde los años setenta ha comprobado la importancia de la escuela en la lengua y en las matemáticas, conclusión derivada de la relación entre el grado de desarrollo medido mediante el producto interno bruto per cápita y el papel de la escuela; ahora podemos afirmar que si bien la escuela es igual de importante en todas las latitudes, parece más urgente y necesaria en los países con menos desarrollo. McLaren (2005) sostiene que el sistema educativo educacional es el nivelador glorioso de nuestra sociedad libre: el éxito puede ser alcanzado por la inteligencia, el trabajo duro y la creatividad. Como muchos mitos, éste forma parte de nuestra percepción diaria aún comprobada su falsedad. Los creyentes de este mito sugieren que la desigualdad resulta de nuestra forma establecida de "meritocracia", que proporciona a los estudiantes más capacitados — que trabajan duro y tienen más inteligencia innata— sus legítimas recompensas y excluye a los que están menos capacitados, incluso algunos de ellos proclaman que la biología está en la raíz de la división de clases; prefieren ignorar o mal interpretar las investigaciones recientes que indican que uno de los determinantes del éxito académico es el ingreso familiar. El mito de la igualdad de oportunidades enmascara por tanto una fea verdad: el sistema educacional es en realidad una lotería social dirigida, en la que cada estudiante obtiene tantas oportunidades como dólares tengan sus padres.

Las posturas en torno a la función social de la escuela son diversas, al grado de ser contrapuestas en algunos autores. Como el objetivo no es ser ecléctico, si no mostrar puntos de vista sobre el rol que han ocupado las escuelas en diferentes momentos y contextos, estos permiten enriquecer una posición, la escuela como cualquier otra institución social, puede desarrollar y reproducir su propia cultura específica; pero por otro lado reconocer que convive en un escenario donde la educación en su carácter de "pública" responde a un modelo universalista que se rige por normas y conductas diseñadas desde afuera. La escuela es un espacio de interacción de muchos elementos 
endógenos y exógenos con alianzas y con resistencias pero con un potencial de beneficio social insustituible.

\section{La escuela como una institución de desarrollo local}

Las instituciones han sido las formas a través de las cuales las sociedades se han puesto de acuerdo para la organización de las actividades. Las instituciones no son propiamente las organizaciones, más bien son las que dan vida a las organizaciones a través de su permanencia. La familia, los gobiernos, la educación, el trabajo, la salud, son instituciones que han evolucionado y han marcado así la propia transformación de las sociedades.

Las instituciones constituyen conjuntos de normas que rigen actividades consideradas básicas para la supervivencia del grupo ${ }^{10}$. Su función es someter el comportamiento individual al control social. Esto implica que dichas normas se convierten en pautas previamente definidas que canalizan el comportamiento en una dirección determinada, en oposición a las muchas otras que podrían darse teóricamente. Una institución, por lo tanto, prescribe la forma en que deben hacerse las cosas. Es una norma social operativa, válida para un determinado grupo social, que reúne tres condiciones: a) Es aceptada por un gran número de miembros, b) muchos de los que la aceptan la cumplen efectivamente, es decir, la han incorporado a sus rutinas de comportamiento, la han "internalizado"; y c) está sancionada, aprobada, o sea, se espera que algunos miembros del sistema se guíen por la norma en circunstancias adecuadas (Brígido, 2006).

Toda institución tiene tres características fundamentales: historicidad, control y objetividad. La historicidad hace alusión al hecho de que las instituciones se han ido conformando gracias a la acción conjunta y continúa de los actores sociales durante un cierto período de tiempo, transcurrido el cual, se han consolidado y como consecuencia de ello, resultan difíciles de cambiar rápidamente. El control se refiere a que las instituciones son pautas consideradas obligatorias por los miembros del (o los) grupo(s) social(es). El resultado de esto es que las instituciones dirigen el comportamiento en una dirección determinada. Por último, la objetividad implica que las instituciones son experimentadas por los actores como si tuvieran realidad propia, similar a un "objeto", como algo externo al individuo y que ejerce coacción sobre su conducta (Brígido, 2006).

Entender a la escuela como una institución de desarrollo local nos obliga a entender el papel que tienen las instituciones en la vida política, económica y social. El institucionalismo y neoins-

\footnotetext{
${ }^{10}$ Hay una segunda acepción del término institución social. Se le usa, generalmente, para designar a un grupo especial. En este sentido se habla de la familia, la escuela, la universidad como instituciones sociales. Aunque ello es perfectamente admisible, es conveniente, distinguir las pautas normativas, de las formaciones sociales a las cuales ellas se aplican. Y esto por dos razones: primero, las formaciones sociales pueden no adecuarse a la norma en todo los aspectos, es decir el comportamiento de los miembros puede desviarse de la norma aceptada; segundo, porque las relaciones en una formación social se rigen por un complejo de pautas que no se agotan en una institución — las relaciones familiares se rigen por pautas que exceden las de la institución del matrimonio, por ejemplo- (Brígido, 2006).
} 

enfoque de las capacidades humanas

titucionalismo han cobrado fuerza en las ciencias sociales en la medida que propone una revaloración del papel de las instituciones, sobre todo aquellas que apoyan la evolución y dinámica de una sociedad, ya que no siempre se crean instituciones favorables, muchas de ellas detienen el progreso. Entendidas éstas como las reglas del juego en una sociedad (North, 2001) ubicaremos a las escuelas como una institución que contribuye positivamente al desarrollo, pero que no está aislada en un sistema local; pertenece más bien a subsistemas y sistemas complejos que trascienden este ámbito y se configuran en dimensiones más amplias (subnacionales o nacionales); sin embargo, la incidencia particular que como institución tiene en un ámbito local es trascendente y multifactorial; esto significa que el impacto de las escuelas está en función de su calidad pero también de la posibilidad de insertarse en las particularidades del contexto local. La escuela vista como una institución de desarrollo local impacta directamente en la creación de un capital cultural, social y productivo favorable para la determinación de iniciativas de desarrollo (Gallichio, 2005).

Existen tres elementos cruciales a la hora de pensar y actuar en el desarrollo local: a) la gobernanza local, regional y nacional.- El desarrollo local mejora la gobernanza en todos sus niveles, básicamente porque pone el gobierno y el poder al alcance de la gente; b) el desarrollo económico local y el empleo.- El desarrollo económico local debe ser discutido y practicado no solamente en su dimensión de crecimiento, sino sobre todo, como una estrategia de generación de empleo y trabajo; y c) la construcción de capital social.- Podemos referirnos al capital social como asociaciones horizontales entre la gente y las redes sociales de compromiso cívico y normas colectivas que tienen efectos en la productividad de la comunidad. El aspecto fundamental del capital social es que facilita la coordinación y la cooperación en beneficio mutuo de los miembros.

El interés manifiesto en los sistemas educativos, en especial el de los países en vías de desarrollo, estriba en el hecho de que se ha comprobado internacionalmente que entre las variables que explican el desarrollo de un país (entendido en un sentido que va más allá que crecimiento económico), la escolaridad de los adultos (también entendida en un sentido amplio más allá que el número de años de asistencia a la escuela) es una variable explicativa relevante ${ }^{11}$. En un análisis de Prawda (2006) se verifica que la variable educativa llega a explicar hasta $20 \%$ de la varianza de las variables relacionadas con desarrollo económico. Esta relación se da en dos dimensiones: 1) la social y 2) la productiva.

Las externalidades sociales del sector educativo son notables en función de la escolaridad, por ejemplo, tenemos el caso de las mujeres de 15 años o más en las regiones marginadas ${ }^{12}$. La relación de asociación (no de causalidad), es que a mayor escolaridad de las mujeres, en particular de las madres de familia, menor la mortalidad y desnutrición infantil, así como la fertilidad y mayor el

${ }^{11}$ Teoría del Capital Humano de Teodoro W. Schultz, Premio Nobel de Economía, en su artículo "Investment in Human Capital", American Economics Review, vol. 51, marzo de 1961.

${ }^{12}$ El análisis se realiza de un estudio sobre externalidades educativas en Uttar Pradesh, India, titulado como Educación, Productividad y Empleo: retos para el sistema educativos. Publicado por Solana en Educación visiones y revisiones 2006. México. 
grado de inmunización de los niños. En condiciones de mayor desarrollo social los efectos educativos son más notables, está documentado que por cada mil niñas entre seis y diez años de edad que reciban un año adicional de escolaridad en India se producen 300 nacimientos menos, 43 muertes infantiles menos y dos muertes menos de madres por efectos del parto. La educación genera externalidades de desarrollo social que se acentúan a medida que el contexto es socialmente más desarrollado. Por otro lado es innegable la externalidad productiva de la educación. Las evidencias internacionales de los países muestran que existe una relación positiva entre variables educativas y productivas.

\section{El desarrollo de escuelas localmente relevantes}

Cuando comenzamos hablar del desarrollo de escuelas localmente relevantes lo primero que intentamos aclarar con lo hasta aquí analizado es la propia concepción como tal, para éste efecto se trató de recurrir a diferentes ámbitos de política educativa y de la academia que trabajan los referentes sobre la relevancia educativa.

El primer informe del Instituto Nacional para la Evaluación de la Educación (INEE, 2007), señala que la calidad del Sistema Educativo Nacional no se reduce solamente a los niveles de aprendizaje que alcanzan los alumnos, sino que incluye otros aspectos como: Relevancia y pertinencia, entendida como la adecuación de la educación respecto a las necesidades de los alumnos a los que se dirige y de la sociedad en que se sitúa. Eficacia interna y externa a corto plazo, que incluyen el acceso de todos los destinatarios a la escuela (cobertura), su permanencia en ella (lo opuesto a la deserción), y su egreso con los niveles de aprendizaje previstos. Eficacia externa de largo plazo o impacto, o sea la asimilación duradera del aprendizaje y su aplicación en comportamientos provechosos en la vida adulta. La suficiencia de los recursos disponibles en las escuelas y la eficiencia de su uso. La equidad, en el sentido de la existencia de apoyos especiales a quienes lo requieran, para que todos alcancen los objetivos.

El mismo instituto señala que el concepto de calidad es relativo, porque los juicios al respecto dependen del referente dinámico, ya que la calidad nunca se alcanza del todo. Esta manera de concebir la calidad, es congruente con los planteamientos más actuales sobre el particular, los cuales se relacionan con la noción del derecho a la educación.

En este sentido puede citarse el siguiente párrafo del más reciente informe sobre los avances del gran proyecto Educación para Todos en la región latinoamericana de la UNESCO, este documento señala que se entiende a la educación de calidad: como la que garantiza el derecho a la educación, abordando exitosamente aspectos vinculados a la relevancia de los aprendizajes de las personas, la pertinencia de las experiencias educativas, la equidad y en qué medida la operación pública logra tener eficacia y es eficiente según la Oficina Regional de Educación para América Latina y el Caribe (OREALC/UNESCO, 2008).

La toma de conciencia de la necesidad de calidad en educación es muy intensa en la actualidad, dentro de una política de la educación de la que se espera asegure la competitividad de las 
El papel de la escuela localmente relevante frente a las actuales teorías del desarrollo. un acercamiento al enfoque de las capacidades humanas

economías nacionales con el aprovechamiento del gran potencial de los recursos humanos, así lo indica el Informe del Comité Consultivo sobre Investigación y desarrollo industrial de la comisión de la Unión Europea (IRDAC) sobre calidad y relevancia (Seminario Internacional de Indicadores Educativos. INEE, 2007).

El programa mundial de la UNESCO, Educación Para Todos (EPT), suscrito por los países miembros define los horizontes deseables para el año 2015, con metas específicas a alcanzar, las cuales contemplan a la educación como un proceso de aprendizaje a lo largo de la vida; de los objetivos propuestos se mencionan: extender y mejorar la protección y educación integral de la primera infancia, especialmente de los niños más vulnerables y desfavorecidos; velar porque, al 2015, todos los niños, y sobre todo las niñas, que se encuentren en situaciones difíciles y los que pertenecen a minorías étnicas tengan acceso a una enseñanza primaria gratuita y obligatoria de buena calidad (Seminario Internacional de Indicadores Educativos, INEE, 2007).

En cuanto a los objetivos del gobierno federal, el Plan Nacional de Desarrollo 2013-2018 establece cinco metas nacionales: México en Paz, México Incluyente, México con Educación de Calidad, México Prospero y México con Responsabilidad Global. Al hacer suya la prioridad de la educación de calidad en una de sus metas nacionales reafirma que las posibilidades de desarrollo de un país dependen de una educación de calidad. El plan afirma que la educación es un derecho humano fundamental que debe de estar al alcance de todos los mexicanos. No basta con dar un espacio a los alumnos en las escuelas de todos los niveles; es necesario que la educación forme para la convivencia, los derechos humanos y la responsabilidad social, el cuidado de las personas, el entendimiento del entorno, la protección del medio ambiente, la puesta en práctica de habilidades productivas y, en general, para el desarrollo integral de los seres humanos.

En el año 2002 los países de América Latina y el Caribe, en conjunto con la Oficina Regional de Educación para América Latina y el Caribe (OREAL/UNESCO Santiago), reunidos en La Habana, Cuba, definieron una estrategia de mediano y largo plazo ajustada a la realidad regional; así los países firmaron el Proyecto Regional de Educación para América Latina y el Caribe (PREALC) ${ }^{13}$ promulgando un cambio de paradigma al trasladar el foco de la acción de los insumos y las estructuras a las personas, de la mera transmisión de contenidos al desarrollo integral de las personas, de la homogeneidad a la diversidad y de la educación escolar a la sociedad educadora. En él se establecen cinco aspectos estratégicos como líneas de acción prioritarias para el desarrollo educativo en la región: 1). Los contenidos y las prácticas de la educación para construir sentidos acerca de nosotros mismos, de los demás y del mundo en que vivimos. 2). Los docentes y el fortalecimiento de su protagonismo en el cambio educativo para que respondan a las necesidades de aprendizaje de los alumnos. 3). La cultura de las escuelas para que éstas se conviertan en comunidades de aprendizaje y participación. 4). La gestión y flexibilización de los sistemas educativos

${ }^{13}$ UNESCO (2002), Proyecto Regional de Educación para América Latina y el Caribe, París: UNESCO. 
para ofrecer oportunidades de aprendizaje a lo largo de la vida. 5). La responsabilidad social por la educación para generar compromisos con su desarrollo y resultados.

Estos focos estratégicos identificados se centran en los sentidos de la labor educativa (relevancia, pertinencia, y equidad), en el sistema como la acción de los sujetos (eficiencia, eficacia y equidad), en la gestión flexible y transparente (pertinencia y eficacia)

Relevancia. Entendida como el ajuste de la oferta de servicios por parte de los sistemas educativos a las necesidades del mundo actual tanto en términos de las competencias para la vida social como del desarrollo individual, a efectos de actuar en el mundo como un sujeto libre y responsable.

Pertinencia. La educación será pertinente en tanto y en cuanto la oferta de servicios de los sistemas educativos tenga la capacidad de ajustarse a las condiciones particulares de las personas y colectividades a las que sirve, en sus correspondientes contextos culturalmente constituidos, de modo que se asegure un apropiado enlace entre la oferta educativa y la cultura, las necesidades, concepciones y prácticas de las personas. Así, la educación ha de ser significativa para las personas de distintos estratos sociales y culturas y con diferentes capacidades para que puedan apropiarse de los contenidos de la cultura mundial y local; deberá transitar desde una pedagogía de la homogeneidad hacia una pedagogía de la diversidad, aprovechando ésta como una oportunidad de enriquecimiento, y por tanto ser flexible y con posibilidad de adaptación a las necesidades y características de los estudiantes y de los diversos contextos sociales y culturales.

Equidad. Se define en relación con la capacidad del sistema educativo de asegurar universalmente el principio de igualdad de oportunidades con relación al derecho a la educación (tanto en el acceso como en los resultados), independientemente de las condiciones preexistentes (sociales, culturales o de otra índole).

Eficacia. Se refiere a la capacidad de los sistemas educativos de poder cumplir con sus objetivos y obligaciones, y desempeñar sus funciones, aspectos que se traducen en términos concretos el derecho a una educación de calidad para toda la población.

Eficiencia. En qué medida se utilizan adecuadamente los recursos respetando el derecho ciudadano a que su esfuerzo material sea tratado de manera apropiada.

Partiendo de la última idea sobre pertinencia educativa en el sentido de considerar una educación para la diversidad, adaptada a las necesidades sociales y culturales de los alumnos es como se toman en cuenta reflexiones alternativas sobre la relevancia educativa para el desarrollo. Reyes Heroles (2006) habla de educar para progresar, entendiendo al progreso como algo que está más allá del simple crecimiento industrial; dejando en claro que es imposible contemplarlo en los territorios de la imaginación sin cruzar por las aportaciones de la sociedad industrial. Educar para la duda que surge de la información y no educar para la afirmación que nace del dogma.

Es interesante como el autor marca a la educación con una disyuntiva ética en la expresión de "civilización", aquí remite el pensamiento de Bertrand Russell en el sentido de que la civilización es capacidad de prever. Prever los alimentos, prever la energía, la contaminación evitable, prever el 
El papel de la escuela localmente relevante frente a las actuales teorías del desarrollo. un acercamiento al enfoque de las capacidades humanas

futuro de los mares, prever la reparación de los bosques y selvas tropicales, prever las migraciones, prever el cambio de las costumbres alimenticias, prever las hambrunas, prever las consecuencias del crecimiento demográfico, prever las presiones espaciales y el impacto de la urbanización millonaria que veremos en las próximas décadas. Prever, prever, prever. La educación es, en esta visión del mundo, un agente civilizatorio.

Por otra parte Alonso (2006) afirma que se está lejos de tener una educación intelectual a la que se sometan los mexicanos y que se centre en el desarrollo del pensamiento, en la capacidad de asociación de ideas, en el ejercicio de la crítica. Pensar cuesta trabajo, suele ser incómodo y no siempre es económicamente rentable. El mundo entero es una nueva era: la del conocimiento. Para montarnos en la cresta de la nueva ola tendremos que inventar un nuevo paradigma educativo que nos enseñe a identificar, analizar y resolver problemas. Idealmente entre los propósitos de la educación debiera estar politizar, no se trata de imponer el adoctrinamiento partidista, se trata de politizar en el sentido de permitir el desarrollo de un sentido crítico o conciencia acerca de las ideas del mundo, para permitir al individuo elegir razonadamente entre opciones de acción social.

El INEE dentro de su filosofía establece que actualizar la calidad y la excelencia son metas deseables de la educación y de toda empresa humana. Nadie está en contra de la excelencia y resulta difícil imaginar una escuela u organización satisfechas de su mediocridad. El problema, radica en que el consenso en la deseabilidad de las mejoras se desvanece al tratar de precisar en qué consiste la superioridad expresada en la idea general de calidad y excelencia y consecuentemente, en cuáles son los medios más apropiados para lograr escuelas excelentes y una educación de calidad. Este hecho conduce a pensar que, a menos que surjan enfoques diferentes del problema, se repetirán los patrones del pasado y nos limitaremos a sugerir que es necesario tratar de crear escuelas excelentes, de calidad, de modo similar o como se trató de crear escuelas reformadas, escuelas innovadoras o escuelas eficaces, cuyo rasgo es la disparidad entre su pretenciosa retórica y la timidez y pobreza de las propuestas de acción

Jociles y Franzé (2008) proponen para la comprensión de la escuela localmente relevante la necesidad de articular dos componentes; escuela y comunidad, agregando como aspecto fundamental el fin: desarrollo. En su proyecto de crear una escuela con "perfiles eminentemente locales" propone que la enseñanza debe de tener un contenido y cualidad tales que aporte competencias básicas, que propicie la vitalidad de la tradición cultural, que motive la toma en consideración de la cultura local y que confiera a los niños y jóvenes la disposición de participar activa y creativamente en la sociedad. Por otra parte Paré y Lazos, (2003) conciben como escuela local-relevante aquella donde existe la inquietud de entender cómo se aborda la interrelación entre el aprendizaje escolar y la reflexión sobre la problemática regional (ambiental, social, cultural) vivida por los niños.

Por otra parte Solana (2005) en su reiterada pregunta: educar ¿para qué? induce a analizar éste tipo de escenarios. Queremos educar ¿para la productividad y para la competencia internacional, o para la solidaridad? ¿Queremos formar mexicanos y mexicanas o solamente personas para el 
mundo globalizado? Educar ¿para la libertad o para la justicia social? Educar ¿para la competencia o para la convivencia?, con esta serie de interrogantes predispone a la reflexión sobre el papel de la educación para el desarrollo de una sociedad justa y equilibrada.

Campos (2006) sostiene que para que la educación se vuelva un factor decisivo, como puede llegar a serlo, en el combate a la desigualdad y la pobreza, hay que buscar una interacción constante entre los propósitos de la educación y los de la comunidad, es mucho lo que se puede hacer en educación si se pone en práctica una propuesta viable de desarrollo, concebido a partir de las necesidades reales de las personas reales y fabricado a su medida, desde abajo y desde los espacios locales. ¿Hasta qué punto puede la escuela poner su pretensión universalista al servicio de la vida local y por ello real de los sujetos?, ¿hasta qué punto puede ser una institución localmente relevante?

La preocupación principal de la propuesta es lograr la participación de la población local. La mayoría de los proyectos son endebles si los actores locales no se transforman en sujetos sociales con capacidad para dirigir su propio desarrollo. La construcción de un sujeto social capaz de orientar las acciones que puedan proporcionar mayor bienestar implica su propia capacidad de encauzar las aportaciones de los agentes externos o de dialogar con sus propuestas para impulsar un proceso de desarrollo regional desde dentro.

Paré y Lazos (2003) afirman que es importante analizar el papel de los agentes externos y de las instituciones locales en la promoción del desarrollo y de una participación autogestiva; donde el eje ha sido la participación de las poblaciones locales, buscando una interacción constante entre los propósitos de la educación y las necesidades de la comunidad. Si se quiere una educación coherente con un país real, es indispensable incorporar a los esfuerzos educativos la reafirmación de las identidades plurales que fueron ignoradas siempre en la formulación de un proyecto centralizador y uniformador. Campos (2006) en su experiencia describe cuando tuvo la oportunidad de conocer de cerca, en Tabasco, México los efectos devastadores que produce sobre una economía campesina una modernización forzada con la aseveración de que la educación informal había jugado antes un papel muy importante, en el aprendizaje de saberes agrícolas, de pesca, de aprovechamiento de manglares, de elaboración artesanal. Cada una de esas actividades ameritaba un aprendizaje de tecnologías y tradiciones, que los jóvenes recibían de los mayores, a lo largo de un entrenamiento prolongado y denso, estrechamente vinculado a la práctica de los diversos oficios. La invasión de la ganadería, primero, y luego de la explotación del petróleo, fueron determinantes, los jóvenes ya no encontraron un lugar en el sistema productivo tradicional, cuyas ocupaciones fueron cayendo en desuso. En las escuelas muchos maestros se sumaban, convencidos, al desprestigio de los valores y la lengua.

Al desplomarse la antigua economía campesina, la educación informal se quebró por su eje, pero la educación escolar, que la sustituyó, siempre fue muy deficiente. Aun los que han cursado formalmente varios grados de primaria apenas saben leer y escribir. Los rudimentos de la educación formal, adquiridos tan precariamente en la escuela, no dotan a los adolescentes indígenas del 
El papel de la escuela localmente relevante frente a las actuales teorías del desarrollo. un acercamiento al enfoque de las capacidades humanas

bagaje necesario para ingresar con equidad de oportunidades a la dura competencia por los escasos empleos que ofrece la sociedad urbana y moderna. En las áreas campesinas más pobres, especialmente si son indígenas, la educación es todavía más deficiente: la desvaloración de los contenidos culturales tradicionales no llega a compensarse con la incorporación, plenamente interiorizada y coherente, de otros valores. La autora sostiene la necesidad de reubicar a los niños en su tradición cultural, acercándolos a la asimilación de los conocimientos abstractos que se imparten en la escuela a partir de puntos de referencia muy concretos, de la vinculación del aprendizaje con lo que es palpable y visible a su alrededor.

Las investigaciones de Paré y Lazos (2003) tratan de explicar el papel de la escuela en las comunidades, examinando la vinculación de la educación formal y no formal en el contexto rural, trabajando la articulación de la educación formal con las comunidades a través de proyectos participativos con los niños y niñas nahuas y mestizos de la sierra, considerando la posibilidad de que la escuela sea un espacio de reflexión sobre el futuro de los recursos locales, tratando de entender las posibilidades y limitantes de la vinculación escuela-comunidad. La escuela es considerada como un ámbito que permite plantear proyectos de educación no formal, donde pueden participar y aprender conjuntamente los padres y las madres de familia, los maestros y maestras y los niños y las niñas de manera inclusiva (Carro, et al., 2014). Para ello se tiene que presentar la situación de marginación en que se encuentran las escuelas y la problemática de enseñanza-aprendizaje, creando un espacio de acción colectiva: comunicación, participación y vinculación con actividades encaminadas a la protección del medio ambiente, realizando capacitación, materiales, talleres, cambios curriculares para elevar el nivel educativo de niños y niñas.

La escuela localmente relevante es aquella que se convierte en un espacio de reflexión del futuro de los recursos locales, donde interactúan los principios de la educación y los de la comunidad; acordes a sus necesidades reales del entorno, con una participación activa y creativa de los ciudadanos, cuya expresión y vitalidad cultural son consideradas; además de promover solidaridad, justicia social, convivencia e identidad para combatir desigualdad y pobreza.

\section{Conclusiones}

Actualmente, el concepto de desarrollo es multidimensional y toda aportación que contribuya a mejorar la calidad de vida de las personas, su bienestar, prosperidad, satisfacción o felicidad debe considerarse como elemento o indicador parte del concepto. En la medida que las personas cumplan sus expectativas o se estén generando las condiciones para tal efecto se está cumpliendo el propósito de encauzar el desarrollo.

El papel de la educación y la escuela sigue en debate debido a que los muchos resultados de transformación que se les han atribuido, siguen pendientes. Se continúa apostando a la educación como factor de progreso, prosperidad y desarrollo, sin embargo es necesaria una reorientación profunda. Los enfoques revisados son finalmente alternativas viables para diferentes contextos y 
no un recetario de propuestas generalizables. El propósito de este artículo representa una propuesta que está sujeta a la discusión más que un imperativo de implementación, empero consideramos que las escuelas deben de jugar un papel de trascendencia en sus contextos a partir de la defensa de sus costumbres e idiosincrasia.

El reconocimiento hacia lo local intenta ser un complemento de aprender a vivir en la era de la globalización con algunas alternativas antes de aislarse a las condiciones imperantes actuales. Esa es la propuesta de las escuelas localmente relevantes.

\section{Bibliografía}

Alburquerque, F. (2003). Curso sobre desarrollo local. Madrid: Instituto de Economía y Geografía, Consejo superior de Investigaciones Científicas.

Alonso, A. (2006). "Educar para el futuro". En: Solana, Fernando. Educación, visiones y revisiones. México: Fondo Mexicano para la Educación y el Desarrollo, Editores Siglo XXI.

Althusser, L. (1974). "La ideología y aparatos ideológicos del Estado". En: La revolución teórica de Marx. Madrid: Siglo XXI.

Arocena, J. (1997). "Globalización, integración y desarrollo local. Apuntes para la elaboración de un marco conceptual”. En: Persona y sociedad. Santiago.

Boisier, S. (1999). Desarrollo Local: ¿De qué estamos hablando? Colombia: Documento Comisionado para la Cámara de Comercio de Manizales.

Brígido, A. M (2006). Sociología de la Educación, Temas y Perspectivas Fundamentales. España: Editorial Brujas.

Campos, J. (2006), “¿Cómo alcanzar la educación para todos?”. En: Solana, Fernando. Educción, visiones y revisiones. México: Siglo XXI, Fondo Mexicano para la Educación y el Desarrollo.

Carro, Adriana et al. (2014). "Educar sin excluir. Una experiencia de educación inclusiva en el estado de Tlaxcala, México". En: Revista nacional e internacional de educación inclusiva, Volumen 7, Número 1 marzo de 2014. España: Universidades de Jaén, Almería, Murcia, Sevilla y Granada.

Durkheim, É. (1974). Educación y Sociología, Primera edición (2006). México: Editorial colofón. Enríquez, I. (2009). La construcción social de las teorías del desarrollo. Un estudio histórico/crítico para incidir en el diseño de las políticas públicas, Serie políticas públicas, Senado de la República LXI legislatura. México: Miguel Ángel Porrúa.

Fernández, T. (2007), Distribución del conocimiento escolar: clases sociales, escuelas y sistema educativo en América Latina. México: El colegio de México.

Gallicchio, E. (2005). "El desarrollo local: cómo combinar gobernabilidad, desarrollo económico y capital social en el territorio". En: El desarrollo local hoy: retos de lo local ante un mundo globalizado,@local.glob.núm.1, Italia.

Instituto Nacional para la Evaluación de la Educación (2007). Panorama educativo de México, 2004. México. 
El papel de la escuela localmente relevante frente a las actuales teorías del desarrollo. un acercamiento al enfoque de las capacidades humanas

Illich, I. (2006). La sociedad desescolarizada. Obras reunidas I. México: Fondo de Cultura Económica.

Jociles, M. I. y A. Franzé (2008). ¿Es la escuela el problema? Perspectivas Socio-Antropológicas de Etnografía y Educación. España: Editorial Trotta.

McLaren, Peter (2005). La vida en las escuelas. Una introducción a la pedagogía crítica en los fundamentos de la educación. México: Siglo XXI.

Nort, D. C. (2001). Instituciones, cambio institucional y desempeño económico, México: Fondo de Cultura Económica.

Organización para la Cooperación y el Desarrollo Económico, Instituto Nacional para la Evaluación de la Educación (2003). Resultados de las Pruebas PISA en México.

OREALC/UNESCO-UIS (2008). Situación Educativa de América Latina y el Caribe: Garantizando la educación de calidad para todos, Informe Regional de Revisión y evaluación del Progreso hacia la Educación para Todos en el marco del Proyecto Regional de Educación (EPT/ PRELAC)-2007, Santiago, Chile.

Paré, Lazos et al. (2003). Escuela rural y organización comunitaria: Instituciones locales para el desarrollo y el manejo ambiental. México: UNAM-CONACyT-Plaza y Valdés Editores.

Poder Ejecutivo Federal (2013). Plan Nacional de Desarrollo 2013-2018. México: Gobierno de la República.

Prawda, J. (2006). "Educación, Productividad y empleo: retos para el sistema educativo". En: Solana, Fernando. Educación, visiones y revisiones. México: Siglo XXI y Fondo Mexicano para la Educación y el Desarrollo.

Reimers, F. (1999). Educación, pobreza y desigualdad en América Latina. (mimeo).

— (2006). Aprender más y mejor. Políticas, programas y oportunidades de aprendizaje en educación básica en México. México: Secretaría de Educación Pública, Fondo de Cultura Económica, Instituto Latinoamericano de la Comunicación Educativa y Escuela de Posgrado de Harvard.

Reyes, F. (2006) "La educación como defensa de la vida". En: Solana, Fernando. Educación, visiones y revisiones. México: Fondo Mexicano para la Educación y el Desarrollo, Siglo XXI editores.

Rodríguez, Salvador (2005). El desarrollo regional. México: Instituto de Investigaciones Económicas, UNAM.

Sarramona, J. (2006). Debate sobre la educación. (Dos posiciones enfrentadas). España: Paidós.

Sen, Amartya (1997). Bienestar, justicia y mercado. Barcelona: Paidós, Instituto de Ciencias de la Educación de la Universidad de Barcelona.

- (2000). Desarrollo y libertad. Barcelona: Planeta.

— y Bernardo Kliksberg (2007). Primero la gente. Una mirada desde la ética del desarrollo a los principales problemas del mundo desarrollado. Barcelona: Editorial Deusto. 
(2010). La idea de la justicia. España: Editorial Taurus.

Solana, F.; (comp.) (2006). Educación, visiones y revisiones. México: Fondo Mexicano para la Educación y el Desarrollo A. C., Siglo XXI editores.

_ et al. (2005). Educar ¿Para qué? México: Fondo Mexicano para la Educación y el Desarrollo A. C., Editores Noriega.

et al. (2005). Educación y Desigualdad. México: Fondo Mexicano para la Educación y el Desarrollo A. C., Siglo XXI Editores.

Recibido: 27/08/14

Dictaminado: 14/01/15

Corregido: 09/02/15

Aceptado: 02/03/15 